\title{
Antimicrobianos en Unidades de Cuidados Intensivos: Uso empírico
}

\author{
CARLOS PÉREZ C.*
}

\section{Antimicrobial agents in Intensive Care Units Empirical Use}

Infections are a main cause of mortality in the Intensive Care Units. At the present moment in Chile there is a predominance of Gram positive species (methicillin resistant Staphylococcus aureus, coagulase negative Staphylococci and vancomycin resistant Enterococcus) and multiresistant Gram negative rods (Klebsiella pneumoniae). A late or incorrect prescription of antibiotics enhances significantly the mortality of these infectious episodes. The introduction of automated blood culture and of rapid identification methods allows the indication of broad spectrum antimicrobial agents as initial empirical prescription making adequate and prompt adjustments for each patient. We summarize the advantages and limitations of new drugs potencially active against these multiresistant isolates: cefepime, carbapenems, the new quinolones, pristinamycin, teicoplanin and linezolid. The prescription of antibiotics must be based in the local epidemiology of nosocomial infections and its pattern of resistance.

Key words: Intensive Care Unit; Nosocomial infections; Multiresistant infections; Treatment

\section{Consideraciones generales}

Las infecciones son la causa más frecuente de muerte en pacientes hospitalizados en unidades de cuidados intensivos ${ }^{1}$. Una de las manifestaciones más frecuentes de la sepsis es la fiebre; sin embargo, en el paciente crítico también se debe considerar en el diagnóstico diferencial a otras causas de origen no infeccioso, tal como se muestra en la Tabla 1. Los microorganismos productores de sepsis han ido cambiando y desde fines de los años '80 las cocáceas Gram positivas son los agentes más frecuentes, seguido por los bacilos Gram negativos y luego hongos $^{1}$. Dentro de las cocáceas Gram (+), destacan Staphylococcus coagulasa (-), S. aureus y Enterococcus sp. Este último presenta una resistencia creciente a los antibacterianos incluyendo vancomicina, lo que ha hecho más difícil el tratamiento de este tipo de infecciones. Estos cambios epidemiológicos deben tenerse presente a la hora de decidir sobre tratamientos antimicrobianos empíricos.

Otro cambio significativo del último tiempo, es el advenimiento de métodos automatizados de diagnóstico microbiológico, lo que ha mejorado la velocidad en la identificación de los microorganismos causales de infección así como la toma de decisiones en tratamiento antimicrobiano en pacientes críticos. Dentro de ellos debemos destacar los hemocultivos utilizando sistemas automatizados, que han disminuido importantemente el tiempo de aislamiento de bac-

Tabla 1 Causas infecciosas y no infecciosas de fiebre en pacientes críticos

Infección de catéteres intravasculares
Sinusitis u otitis media (especialmente pacientes
con dispositivos intranasales tales como SNE)
Colecistitis alitiásica
Fiebre por drogas
Tromboembolismo pulmonar
Trombosis venosa profunda
Fiebre central (ej. Pacientes con TEC)
Colitis por Clostridium difficile
Síndrome post-pericardiotomía
Infecciones secundarias por microorganismos re-
sistentes
Infecciones fúngicas

Departamento de Medicina. Programa de Enfermedades Infecciosas. Pontificia Universidad Católica de Chile.

Email: cape@med.puc.cl 
terias. En nuestra experiencia en la Pontificia Universidad Católica de Chile, los tiempos de aislamiento para bacilos Gram (-)s son tan cortos como 2 horas para Klebsiela pneumoniae por ejemplo. En el caso de cocáceas Gram positivas como Enterococcus, se puede tener crecimiento ya a las 3 horas de incubación. Ello, sumado a los métodos de identificación rápida presuntiva tales como aureasa para diferenciar entre Staphylococcus coagulasa (-) y $S$. aureus o test de látex para diferenciar entre cocáceas en cadena, permiten ajustar los esquemas de tratamiento antibacteriano empírico a las pocas horas de que el paciente ha iniciado el cuadro séptico. Los métodos automatizados de identificación y susceptibilidad también han contribuido a reducir los períodos de identificación del agente causal de infecciones graves. Por último la aparición de métodos de diagnóstico rápido mediante la identificación de antígenos o toxinas, así como las técnicas de biología molecular, nos están permitiendo reducir las posibilidades de error en la toma de decisiones de tratamiento antimicrobiano empírico.

\section{Impacto en la mortalidad del uso inapropia- do de antimicrobianos en pacientes críticos:}

En un estudio de Mort y Yeston se practicaron autopsias en 149 adultos fallecidos en una unidad de cuidados intensivos quirúrgicos. En $51 \%$ se encontraron errores diagnósticos mayores o menores. El 85\% de los errores diagnósticos mayores fueron infecciones no diagnosticadas ${ }^{2}$. Existen varios estudios que demuestran que el uso inapropiado de antimicrobianos en neumonía asociada a ventilación mecánica aumenta la mortali$\mathrm{dad}^{3}$. Valles y cols efectuaron un estudio prospectivo, multicéntrico de 339 pacientes críticos con bacteriemia adquirida en la comunidad. Se encontró una mortalidad cruda de 41,5\%, falleció de shock séptico $55 \%$ de los pacientes. Los agentes más frecuentes fueron Escherichia coli, S. aureus y Streptococcus pneumoniae. Se utilizó antibacterianos inapropiados en $14,5 \%$ de los casos. El análisis multivariado mostró que el uso inapropiado de antibacterianos entre otros, se asoció a mortalidad (OR 4,11). La mortalidad atribuible a uso inapropiado de antibacterianos aumentó según APACHE II score: 10,7\% con APACHE $<15$ y $41,8 \%$ con APACHE $\geq 25^{4}$. Por lo tanto el uso de antibacterianos empíricos inapropiados aumenta la mortalidad en pacientes críticos afectados de diferentes tipos de infección. Para disminuir el riesgo de utilizar antimicrobianos empíricos inactivos contra los agentes causales de la sepsis, se debe conocer muy cercanamente la epidemiología local en lo relativo a agentes y patrones de resistencia. Esta información está disponible en los Comités de Infecciones Intrahospitalarias de cada institución y también a través de redes de vigilancia de resistencia tales como PRONARES y más recientemente la Red Nacional de Vigilancia de Resistencia del Instituto de Salud Pública y Sociedad Chilena de Infectología.

\section{Principios generales del uso empírico de antimicrobianos en UCI:}

A la hora de decidir sobre el uso empírico de antimicrobianos se debe considerar los siguientes principios: Los agentes deben ser bactericidas. Se debe utilizar habitualmente combinación de antibacterianos. Los antibacterianos deben ser de amplio espectro de acuerdo al cuadro clínico y a la epidemiología local. En infecciones adquiridas en la comunidad, los «nuevos» antimicrobianos no son mejores que los tradicionales.

\section{Antibacterianos de más reciente incorpora- ción utilizados en pacientes críticos:}

\section{Agentes activos contra bacilos Gram negativos}

Meropenem (Meronem ${ }^{\circledR)}$ ): Carbapenémico bactericida, con excelente penetración dentro de las bacterias, con alta afinidad por PBPs y muy estable frente a $\beta$-lactamasas de bacilos Gram negativos. Se excreta por vía renal (requiere ajuste dosis en insuficiencia renal), vida media 1 $\mathrm{h}$ y no es degradado por la dihidropeptidasa-1 tubular renal (no requiere adicionarle inhibidor como cilastatina). Se hemodializa. Es activo frente a cocáceas Gram positivas (menos que imipenem), bacilos Gram negativos (igual o superior a Imipenem) y anaerobios. Está indicado en neumonía, meningitis bacteriana aguda, infecciones intraabdominales, infecciones urinarias, bacteriemia y episodios de neutropenia febril en pacientes con Ca. Los efectos adversos más frecuentes son hipersensibilidad, diarrea por Clostridium difficile y tiene una mucho menor incidencia de convulsiones que imipenem.

Cefepime (Maxipime®): Es una cefalosporina de cuarta generación, bactericida, con actividad sobre bacterias Gram positivas similar a cefotaxima y sobre bacilos Gram negativos comparable a ceftazidima. Tiene excelente penetración a bacterias Gram negativas y baja afinidad por $\beta$-lactamasas. La vida media es de $2 \mathrm{~h}$ 
(dosificación cada $12 \mathrm{~h}$ ), tiene excreción renal de $\sim 80 \%$. Las reacciones adversas son poco frecuentes. Se utiliza en el tratamiento empírico de episodios de neutropenia febril, neumonía nosocomial, infecciones intraabdominales y otros cuadros infecciosos graves.

\section{Agentes activos contra cocáceas Gram positivas}

Nuevas fluoroquinolonas: La mayor ventaja de las nuevas fluroquinolonas como levofloxacina, gatifloxacina (Gatiflox®) y moxifloxacina (Avelox ${ }^{\circledR}$ ) son su mejor actividad sobre $S$. pneumoniae, incluyendo aquellas cepas con algún grado de resistencia a penicilina.

Teicoplanina (Targocid®): Es un glicopéptido bactericida que inhibe la síntesis de la pared bacteriana al alterar la polimerización de los peptidoglicanos en forma similar a vancomicina, pero en un sitio distinto al de los $\beta$-lactámicos (forma complejo con el precursor terminal Dalanil-D-alanina). Tiene mayor lipofilia que vancomicina. Posee excreción renal predominante, con una vida media de 40 a 70 hr Permite administración intramuscular 1 vez al día. Es activa frente a cocáceas Gram positivas (incluyendo Staphylococcus aureus resistente a meticilina -SAMR- y E. faecium resistente a vancomicina Van B), Clostridium sp, Listeria sp y Corynebacterium jeikium.

Las principales indicaciones son:

las infecciones graves por cocáceas Gram positivas, incluyendo SAMR tales como neumonía, bacteriemias, infecciones de tejidos blandos y osteomielitis.

Infecciones por E. faecium resistente a vancomicina Van B. Hipersensibilidad a vancomicina.

Los efectos adversos son poco frecuentes y tiene un menor riesgo de hipersensibilidad, ototoxicidad y nefrotoxicidad que vancomicina. Puede producir flebitis.

Pristinamicina (quinupristina/dalfopristina) (Synercid ${ }^{\circledR}$ ): Es un derivado de la estreptogramina pristinamicina IA y IIB y pertenece a la familia de los macrólidos-lincosaminas-estreptograminas. Es bactericida o bacteriostático. Actúa inhibiendo la síntesis proteica bacteriana por unión a subunidad 50S (quinupristina inhibe elongación de la cadena peptídica y dalfopristina interfiere con la peptidil transferasa). Es activo frente a cocáceas Gram positivas (incluyendo SAMR y E. faecium resistente a vancomicina), anaerobios, Listeria sp, Chlamydia sp, Mycoplasma sp. Po- see excreción biliar predominante, con una vida media de $1 \mathrm{~h}$ para quinupristina y $0,75 \mathrm{hr}$ para dalfopristina.

La principales indicaciones son las infecciones por E. faecium resistente a vancomicina o teicoplanina. Los efectos adversos más frecuentes son flebitis, náuseas, vómitos, diarrea y rash.

Linezolid (Zyvox®): Es un antibacteriano verdaderamente nuevo, bacteriostático, perteneciente a la familia de las oxazolidinonas. Interfiere con la formación del complejo de iniciación en la síntesis proteica ribosomal bacteriana. Es activo contra cocáceas Gram positivas, incluyendo resistentes a $\beta$-lactámicos.

Se ha utilizado con éxito en neumonía nosocomial incluyendo aquellas causadas por SAMR, pacientes hospitalizados con neumonía grave adquirida en la comunidad, las infecciones complicadas de piel o tejidos blandos incluyendo las producidas por SAMR y las infecciones por E. faecium resistente a vancomicina en cualquier sitio incluyendo bacteriemia.

\section{Conclusiones}

Se deben considerar causas infecciosas y no infecciosas en el diagnóstico diferencial de la fiebre en pacientes críticos.

Hay un aumento de las bacterias Gram positivas como causas de infección en este grupo de pacientes.

El tratamiento antimicrobiano inapropiado aumenta la mortalidad.

Los nuevos métodos de diagnóstico microbiológico acortan el tiempo de identificación del agente causal.

El tratamiento antimicrobiano empírico se debe basar en la epidemiología local y debe incluir los mejores agentes bactericidas para los microorganismos más probables.

\section{Resumen}

Las infecciones son causa importante de mortalidad en las unidades de cuidados intensivos. Actualmente predominan en Chile las causadas por cocáceas Gram positivas (Staphylococcus aureus resistente a meticilina, Staphylococcus coagulasa negativa y Enterococcus resistente a vancomicina) y en segundo lugar bacilos Gram negativos multiresistentes (Klebsiella pneumoniae). Una indicación antimicrobiana tardía o errada eleva significativamente la letalidad de las infecciones en estas condiciones. La introducción de métodos automatizados de hemocultivos 
y de técnicas de rápida identificación microbiana permiten emplear antimicrobianos de amplio espectro en una indicación empírica inicial y efectuar rápidos ajustes terapéuticos adecuados a cada situación. Se revisan someramente las bondades y limitaciones de nuevos antimicrobianos potencialmente útiles en estas situaciones: cefepime, carbapenems, nuevas quinolonas, pristinamicina, teicoplanina y linezolid. La indicación de antimicrobianos debe fundamentarse en la epidemiología local de resistencia en las infecciones de origen nosocomial.

\section{Bibliografía}

1.- Hotchkiss R S, Karl I E. The pathophysiology and treatment of sepsis. N Engl J Med 2003; 348: 138-50.

2.- Mort TC, Yeston NS. The relationship of pre mortem diagnoses and post mortem findings in a surgical intensive care unit. Crit Care Med 1999; 27: 235-6.

3.- Alvarez A, Bavestrello L, Labarca J. Tratamiento de la neumonía asociada a ventilación mecánica. Rev Chil Infectol 2001;18, Supl 2: 58-65.

4.- Valles J, Rello J, Ochagavía A et al. Communityacquired bloodstream infection in critically ill patients. Impact of shock and inappropriate antibiotic therapy on survival. Chest 2003;123: 1615- 24. 